\author{
على اسكندرى'، فرشاد فرامرزيان ياسوجَ، اباذر سُلكَى 'و حيدر زارعى

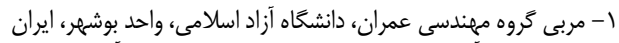

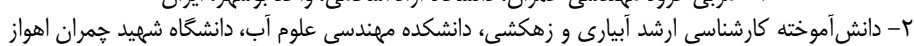

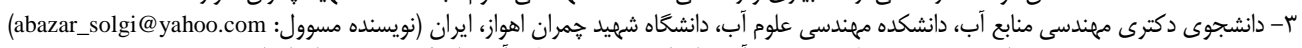

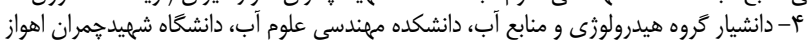 \\ تاريخ بذيرش:

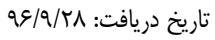

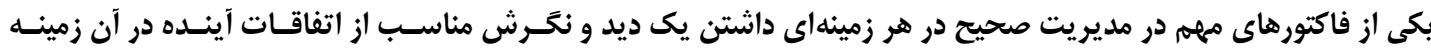
جكيده



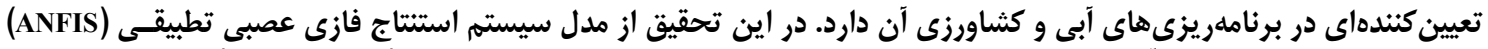

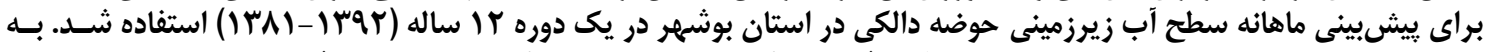

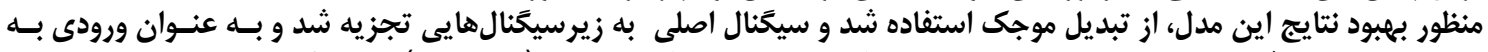



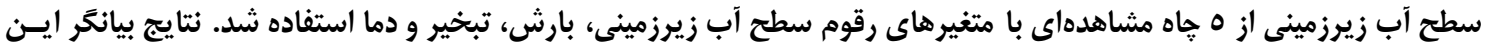

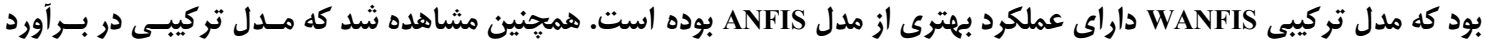

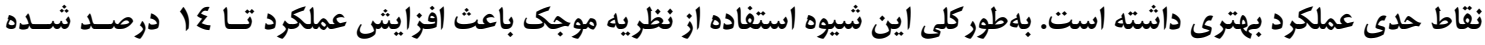

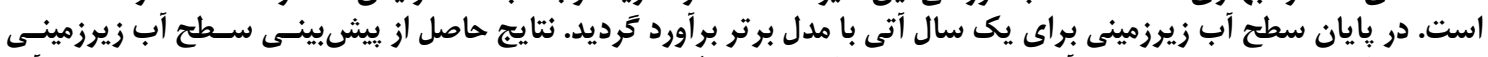

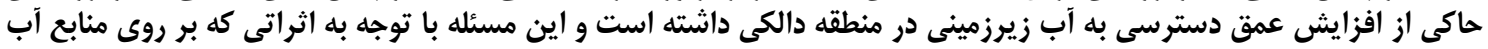

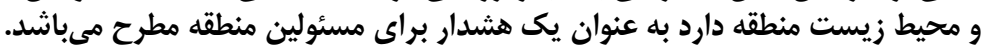

وازههاى كليدى : مدل تركيبى، تبديل موجك، سطح آب زيرزمينى، حوضه دالكى، مدلسازى و ييشبينى

حاصل از اين مدل با مدلهاى ANN و

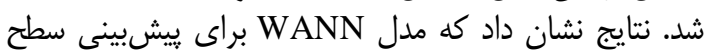

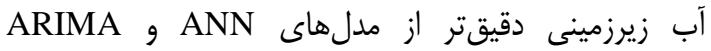

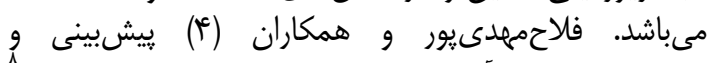
شبيهسازى سطح آب زيرزمينى بوسيله برنامهريزى زئل زنتيك نائ (GP)

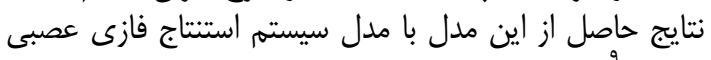


نشان داد كه ييشيينى و شبيهسازى توسط روش

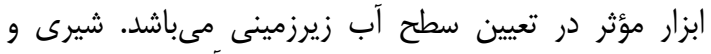

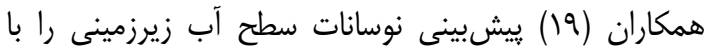

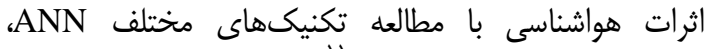
ANFIS

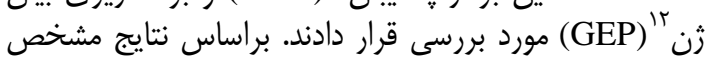

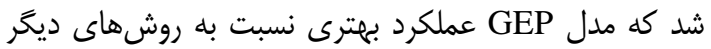

$$
\text { داشته است. }
$$

سوريانارايانا و همكاران (T) يك (T) يك تركيب ماشين بردار

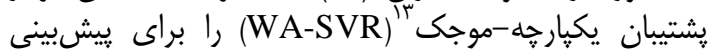
نوسانات ماهانه سطح آب زيرزمينى در ويشاكاياتنام، هند مورد

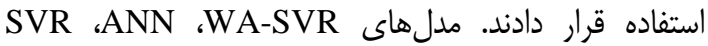



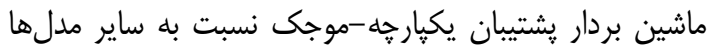

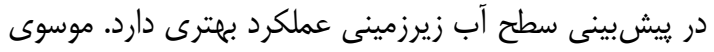

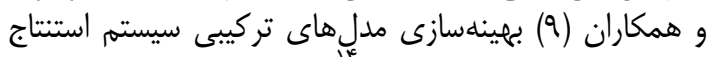
فازى عصبى تطبيقى -موجك (WANFIS) و
مقدمه آًَاهى از نوسانات سطح آب زيرزمينى در كشور ايران به

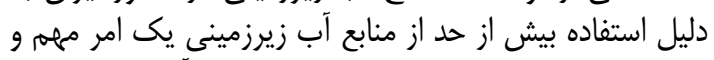

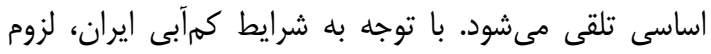

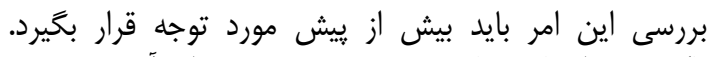

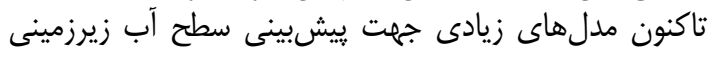

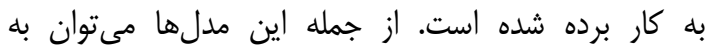



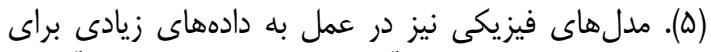

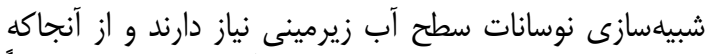

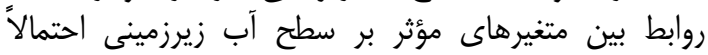

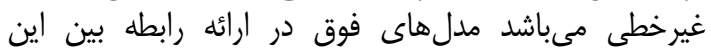



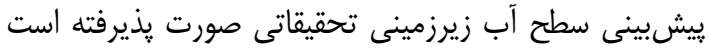

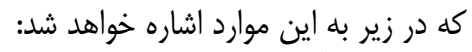



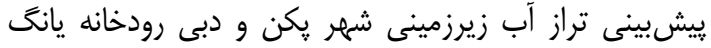

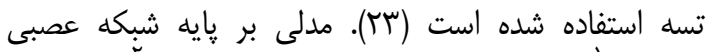

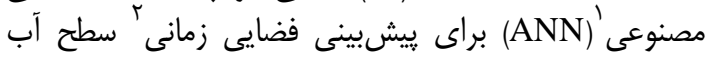

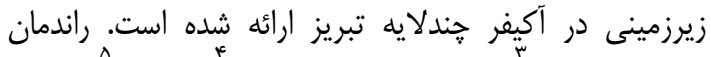

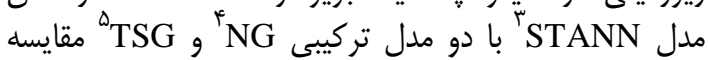

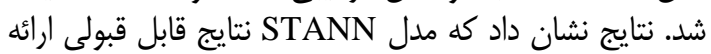

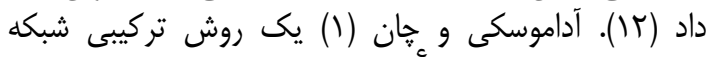


ماهانه سطح آب زيرزمينى استفاده كردند.در اين تحقيق نتايج

\footnotetext{
1- Artificial neural network 2-Spatiotemporal 3-Spatio-temporal ANN 4- Neural-geostatistics

5- Multivariate time series-geostatistics 6- Wavelet- ANN

8- Genetic programming 9-Adaptive neural fuzzy inference system

$11-$ Gene expression programming $\quad 12-$ Gene expression programming

7- Autoregressive integrated moving average

14- Wavelet-ANFIS
} 
رزئولوزيكى مختلفى نياز دارند. در اين مدلها شناسايى شرايط

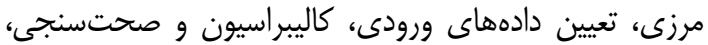

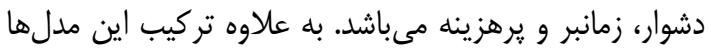

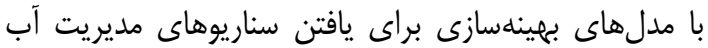

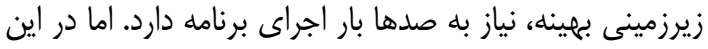

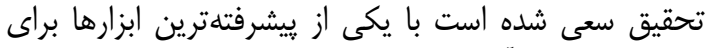

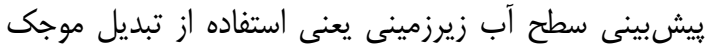

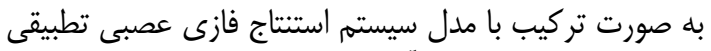



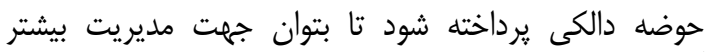
آبهاى زيرزمينى كامى مؤثر برداشت.

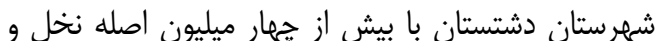

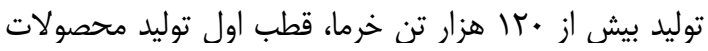

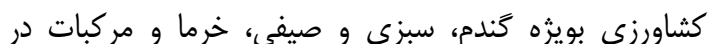

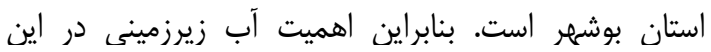

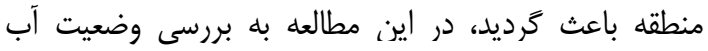
زيرزمينى دشستستان برداخته شود.

\section{مواد و روشها موردا منطقه مورد مطالعه}

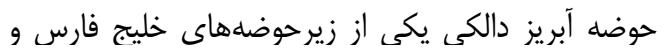

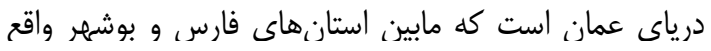

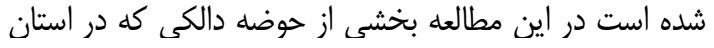
بوشهر و شهرستان دشتستان واقع شده است مورد مطالعه قرار التهار كرفته است.

يكى از مشكلات مهر در سطح شهرستان دشتستان و و

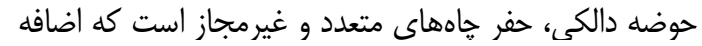

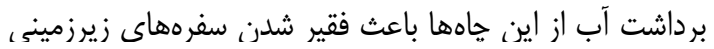

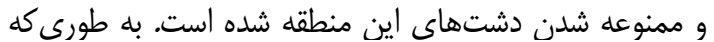

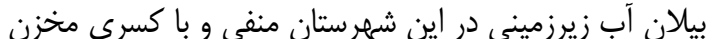

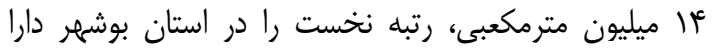

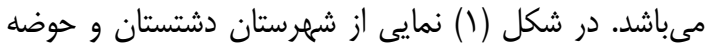

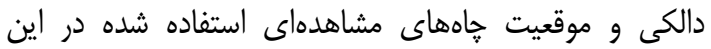

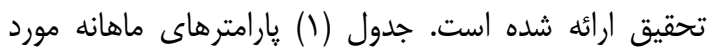

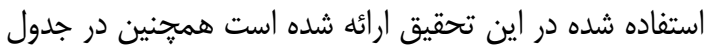
(T) مشخصات خاههاى مورد استفاده آورده شده است است.
بوسيله روش تاكوجى را براى بيشيبنى سطح آب زيرزمينى

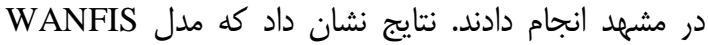

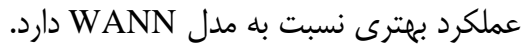


براى مدلسازى سطح آب زيرزمينى مورد استفاده قرار دادئن إداند.

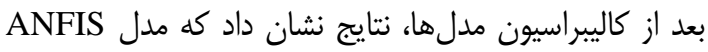

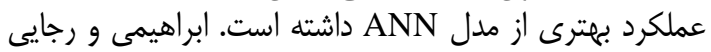

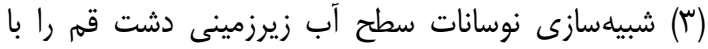

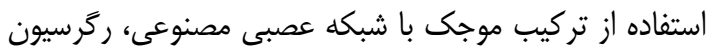

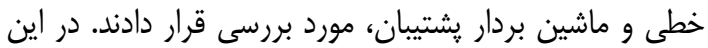

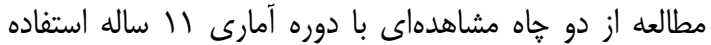

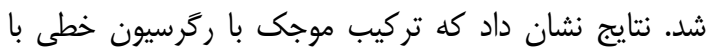

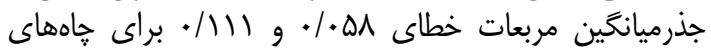
يك و دو داراى بهترين عملكرد بوده است.

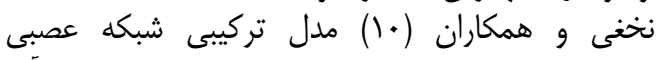

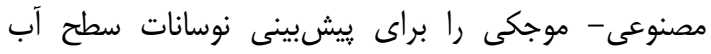
زيرزمينى دشت قروه مورد استفاده قرار دادند. نتايج نشان دان داد

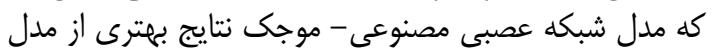


سطح آب جايكزين MODFLOW شود. رجايى و زينىوند زيند

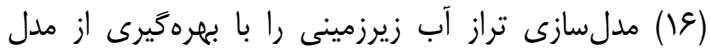

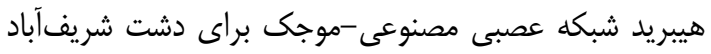



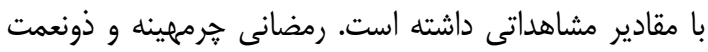

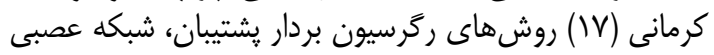

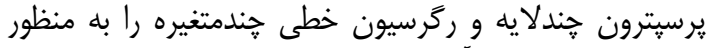

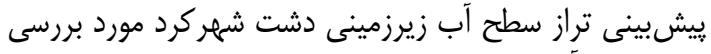

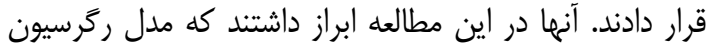

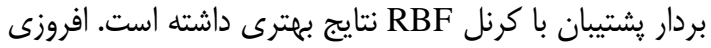





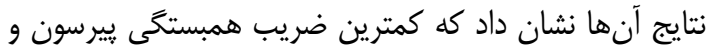

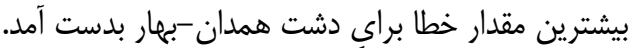

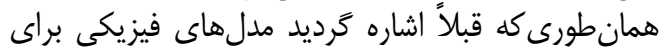

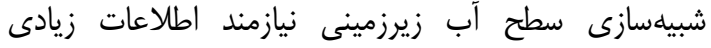
هستند، مدلهاى عددى نيز به بارامترهاى هيدرولوزيكى و و 


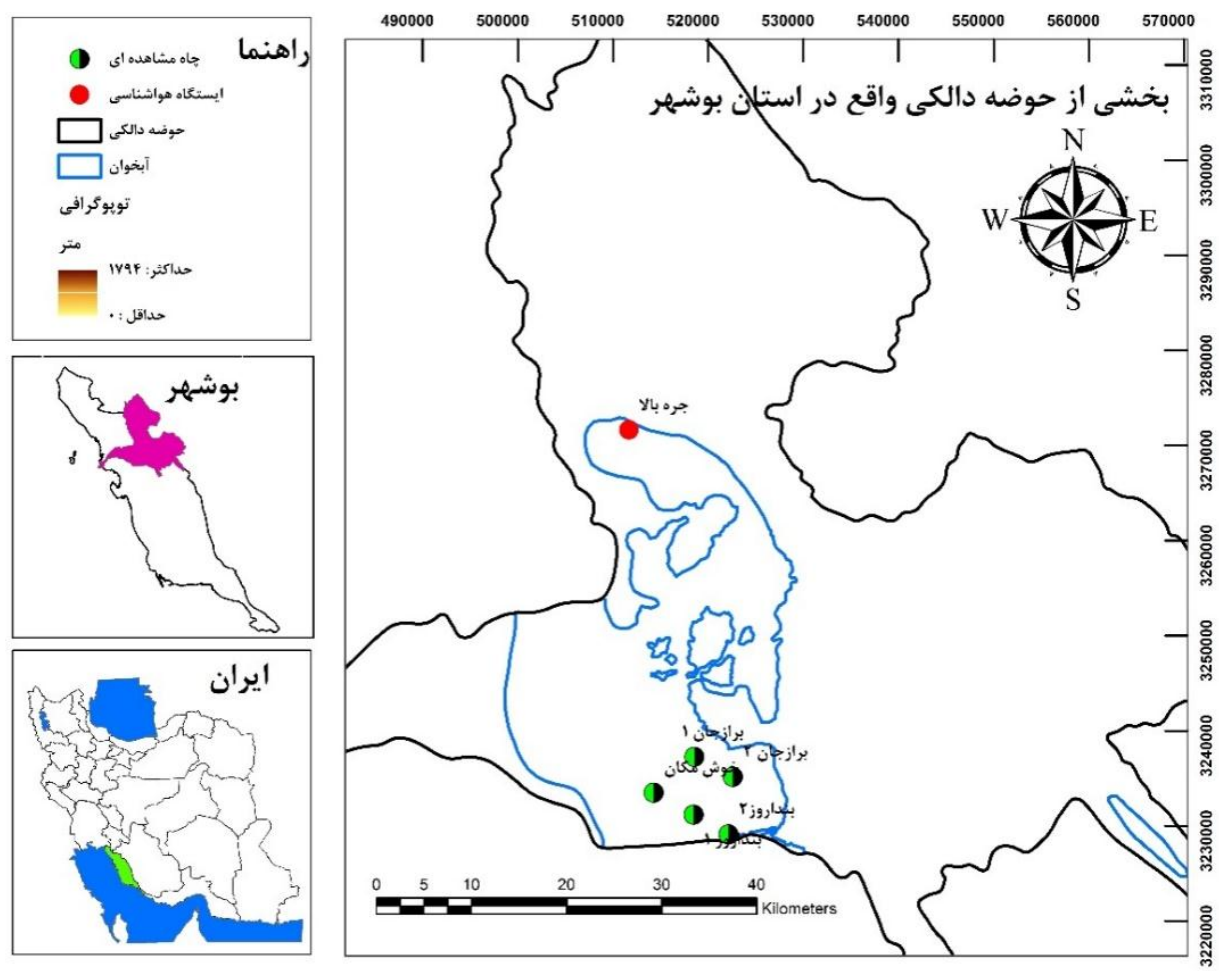

شكل 1- موقعيت خاه هاى حوضه دالكى

Figure 1. Location of Dalki basin wells

Table 1. Meteorological monthly variables in period (2002- 2013)



\begin{tabular}{|c|c|c|c|c|c|c|c|c|}
\hline \multirow{2}{*}{ ارتفاع از سطح دريا } & \multicolumn{2}{|c|}{ مشخصات جغرافيايى } & \multirow[t]{2}{*}{ حداقل } & \multirow[t]{2}{*}{ حداكثر } & \multirow[t]{2}{*}{ ميانگين } & \multirow[t]{2}{*}{ متغير اقليمى } & \multirow[t]{2}{*}{ كد ايستگاه } & \multirow[t]{2}{*}{ نام ايستخاه } \\
\hline & عرض & طول & & & & & & \\
\hline 1.9 & "א ' & $\Delta 1^{\circ} \cdot V^{\prime} \mid I^{\prime \prime}$ & $\begin{array}{l}. \% \\
. \% \\
. \%\end{array}$ & $\begin{array}{l}r \Delta \cdot / . . \\
r V / \cdot . \\
V Q T / T .\end{array}$ & 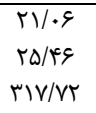 & 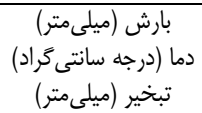 & $r r-.11$ & جره بالا \\
\hline
\end{tabular}

Table 2. Characteristicsof wells used in this study

جدول r- مشخصات خاههاى مورد استفاده در اين تحقيق

\begin{tabular}{|c|c|c|c|c|c|c|c|c|}
\hline \multirow{2}{*}{ 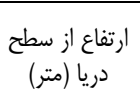 } & \multicolumn{2}{|c|}{ (درجه، دقيقه، ثانيه) } & \multicolumn{3}{|c|}{ مقياس ماهانه } & \multirow[t]{2}{*}{ متغير } & \multirow[t]{2}{*}{ نام קاه } & \multirow[t]{2}{*}{ جاه } \\
\hline & عرض & طول & حداقل & حداكثر & ميانگ̌ين & & & \\
\hline re & $r q^{\circ} \mid r^{\prime \prime} \times q "$ & $\Delta 1^{\circ} \cdot \Lambda^{\prime}+q "$ &.$\%$ & 8 & $r / q \mu$ & سطح آب زيرزمينى (متر) & خوش مكان & 1 \\
\hline$\Delta$. & "سז'זו "צי" & $\Delta 1^{\circ} \| I^{\prime} r \Delta "$ &.$/$ & $11 / 91$ & $q / \wedge$. & سطح آب زيرزمينى (متر) & بنداروز & r \\
\hline vT & r" & "أع'ا" &. & $r q / v 1$ & ( & سطح آب زيرزمينى (متر) & بنداروز & r \\
\hline Fa & $r q^{\circ}\left|Q^{\prime} \Delta\right|^{\prime \prime}$ & $\Delta 1^{\circ} \| 1^{\prime} r V^{\prime \prime}$ &.$/$ & $q / \Delta F$ & $9 / \Delta S$ & سطح آب زيرزمينى (متر) & برازجان & r \\
\hline 99 & "ra & $\Delta 1^{\circ} \mid r^{\prime \prime} \Delta V^{\prime \prime}$ &.$\%$ & $09 / 19$ & $\Delta \& / \Gamma$. & سطح آب زيرزمينى (متر) & برازجان & $\Delta$ \\
\hline
\end{tabular}

$y=0.5+\left(0.5 \times\left(\frac{x-\bar{x}}{x_{\max }-x_{\min }}\right)\right)$

(1)

به علت اينكه وارد كردن دادهها به صورت خام باعث كاهش سرعت و دقت مى شود از روش استانداردسازى دادي دادهها

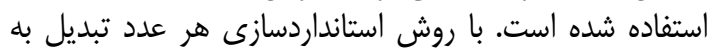

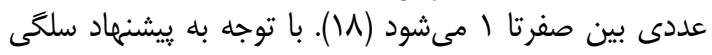

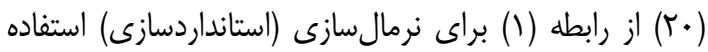




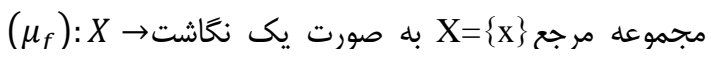

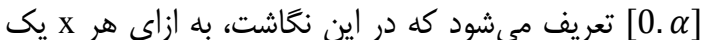

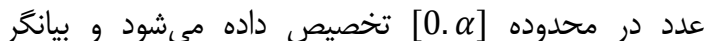
مقدارى است كه اختصاص داشتن x را به مجموعه F ماده نشان تعيين نوع تابع عضويت

معروفترين توابع عضويت كهو دايت در ساختار سيستم استنتاج

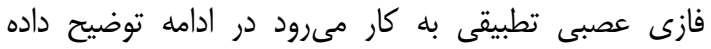

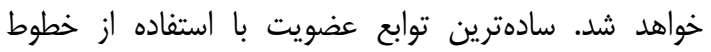

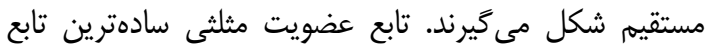



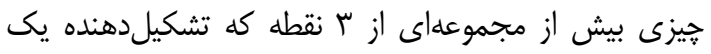

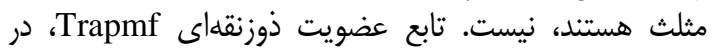

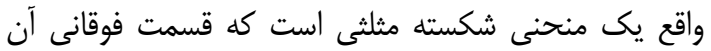

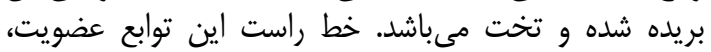

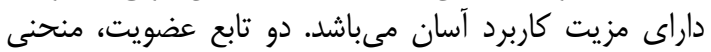



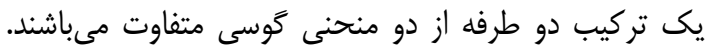

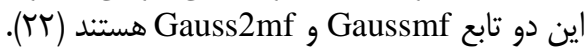



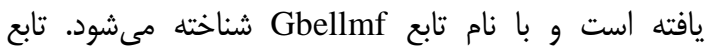

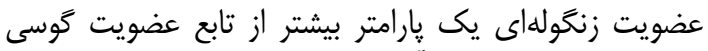

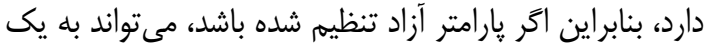

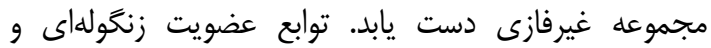



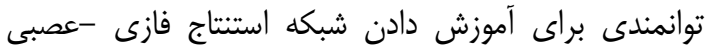

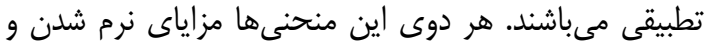

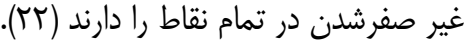

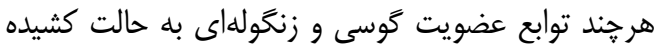

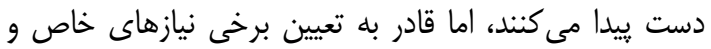

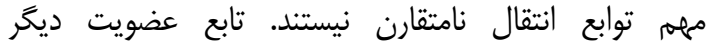

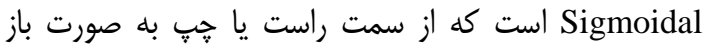

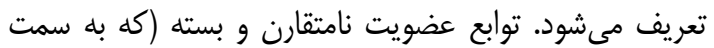





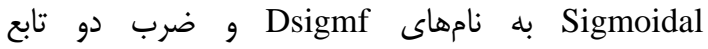

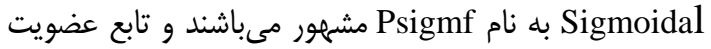

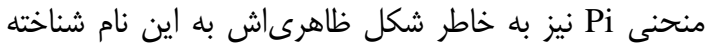

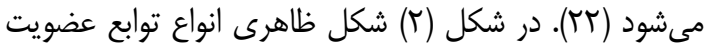
ارائه شده است. - ابت.

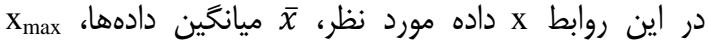

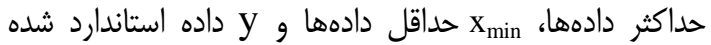

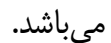

سيستم استتاج فازى عصبى تطبيقى (ANFIS)

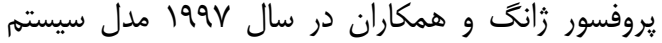

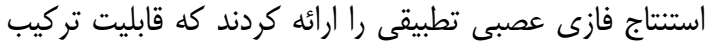

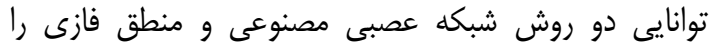

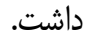

اين روش به طور عملى در زمينه مهيندسى توسعه يافته


جديد براى ييشبينى رواناب معرفى شده است (و) (و). سيسته استتاج عصبى فازى تطبيقى از الكوريتهمهاى يادئيرى شئى شبكه

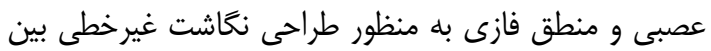

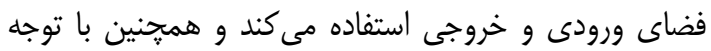

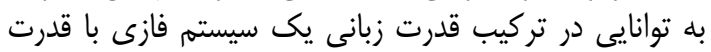



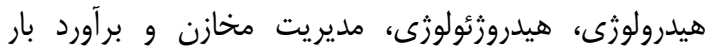



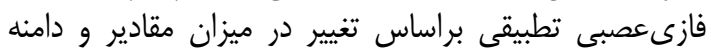

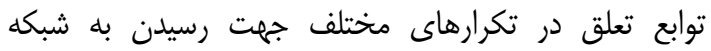

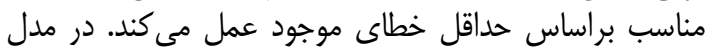

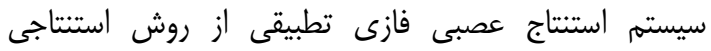

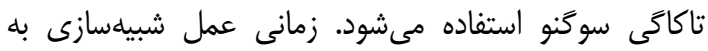

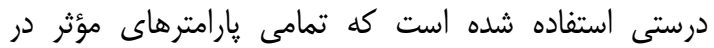

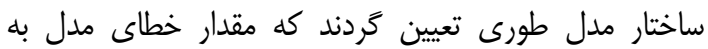

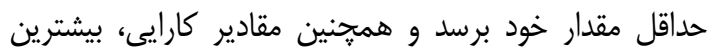

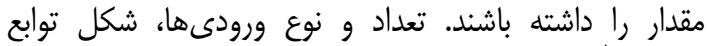


توابع عضويت



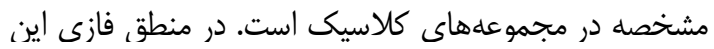

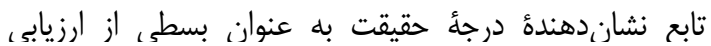







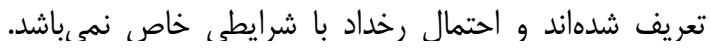

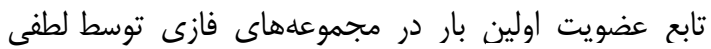

زاده معرفى گرديد (بائ آبار).

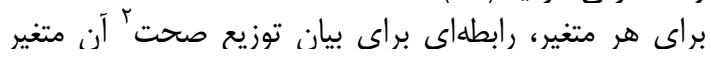

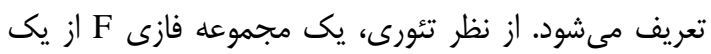




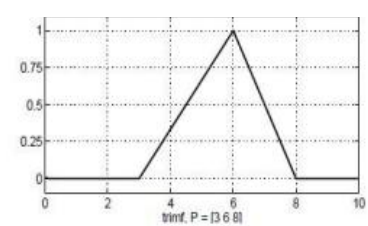

trimf

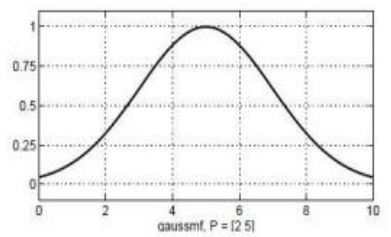

gaussmf

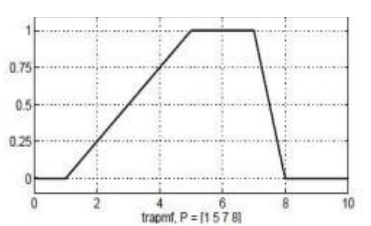

trapmf

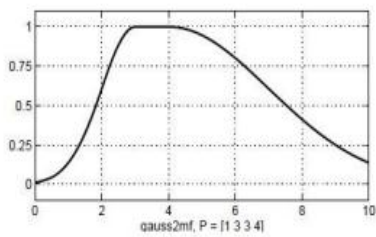

gauss $2 \mathrm{mf}$

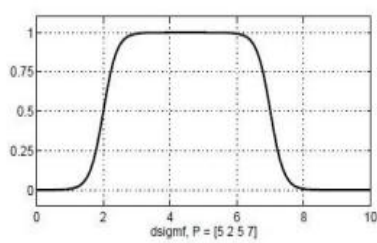

dsigmf



pimf

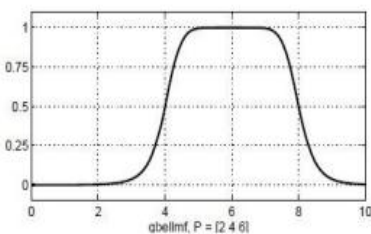

gbellmf

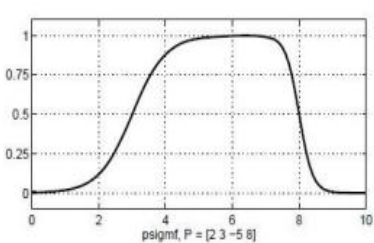

psigmf

شكل r- توابع عضويت

Figure 2. Membership Functions

$\int_{-\infty}^{+\infty} \psi(t) d(t)=0$

(

از انواع موجكهاى مادر كه براى آناليز سيكنال استفاده

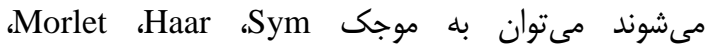
Meyer Daubechies(db) استفاده از تأخير و تغيير مقياس موجى مادر از فرمول زير الماردا

حاصل مى گر دد (^).

$$
\begin{aligned}
\psi_{(a, b)}(t) & =|a|^{-0.5} \psi\left(\frac{t-b}{a}\right), \\
& \\
& a \in R, b \in R, a \neq 0
\end{aligned}
$$

\section{ساختارهاى مختلف جهت مدلسازى باري}

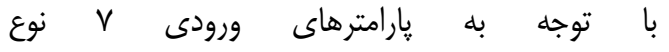

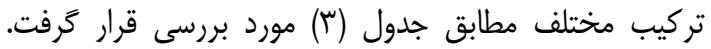
يارامترهاى و سطح آب زيرزمينى در دوره زمانى ماهانه و dب $\quad \mathrm{H}_{\mathrm{t}-2}, \mathrm{H}_{\mathrm{t}-1}, \mathrm{P}_{\mathrm{t}-2}, \mathrm{P}_{\mathrm{t}-1}, \mathrm{~T}_{\mathrm{t}-2}, \mathrm{~T}_{\mathrm{t}-1}, \mathrm{E}_{\mathrm{t}-2}, \mathrm{E}_{\mathrm{t}-1}$ ترتيب تبخير، دما، بارش و سطح آب زيرزمينى در ماههاى



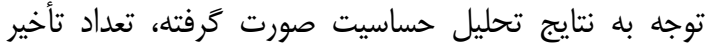

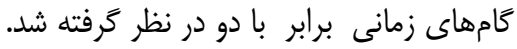

براى اجراى مدل سيستم استتناج فازى عصبى تطبيقى از

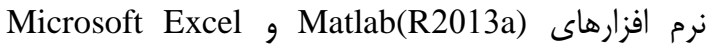
2013 استفاده شده است.

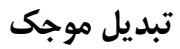
به هر كميت متغير در زمان يا مكان كه قابل اندازهكيرى

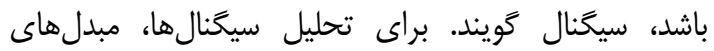

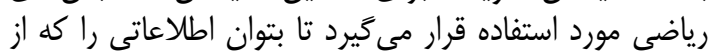

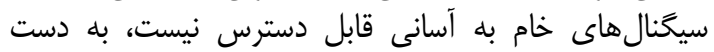

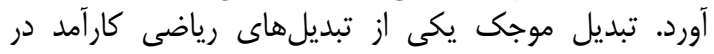

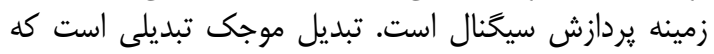

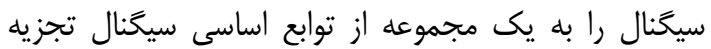

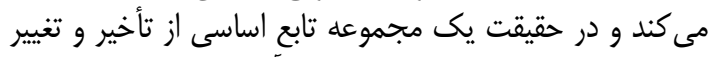

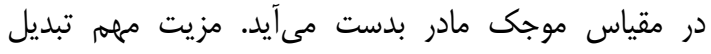

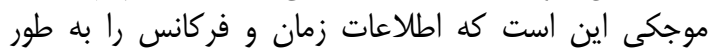

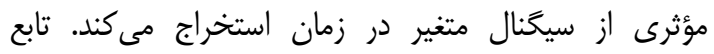

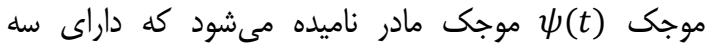

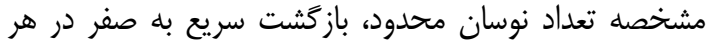

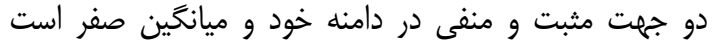

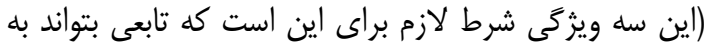

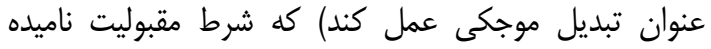
مىشود. تابع موجى (t) باله به شكل رياضى زير تعريف

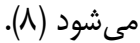


Table 3. Details of combinations of ANFIS model

$$
\text { جدول س- جزئيات تركيبهاى مختلف مدل سيستم استنتاج فازى عصبى تطبيقى }
$$

\begin{tabular}{|c|c|c|}
\hline 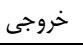 & 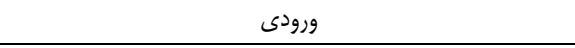 &  \\
\hline$H_{t+1}$ & $H_{t-2}, H_{t-1}, H_{t}$ & 1 \\
\hline$H_{t+1}$ & $P_{t-2}, P_{t-1}, P_{t}$ & r \\
\hline$H_{t+1}$ & $T_{t-2}, T_{t-1}, T_{t}$ & r \\
\hline$H_{t+1}$ & $E_{t-2}, E_{t-1}, E_{t}$ & f \\
\hline$H_{t+1}$ & $H_{t}, P_{t}, T_{t}, E_{t}$ & $\Delta$ \\
\hline$H_{t+1}$ & $H_{t-1}, H_{t}, P_{t-1}, P_{t}, T_{t-1}, T_{t}, E_{t-1}, E_{t}$ & \& \\
\hline$H_{t+1}$ & $H_{t-2}, H_{t-1}, H_{t}, P_{t-2}, P_{t-1}, P_{t}, T_{t-2}, T_{t-1}, T_{t}, E_{t-2}, E_{t-1}, E_{t}$ & $\checkmark$ \\
\hline
\end{tabular}

موجكهاى مادر مختلف و توجه به نكته كفته شده در بالا س

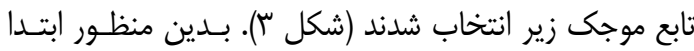

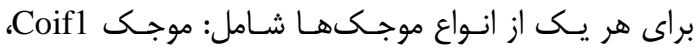

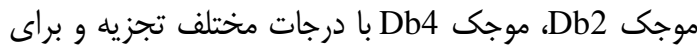
توابع عضويت مختلف برنامه اجرا شد.

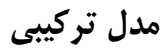

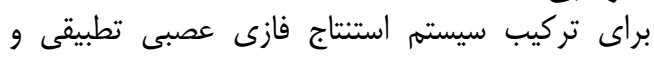

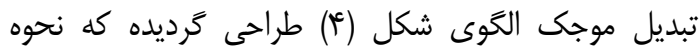
ورود دادهها و خروجى به صورت شمات شاتيك در آن نشان داده شده است.
براى دستيابى به نتايج حاصل از مدل تركيبـى، ابتـدا بـا

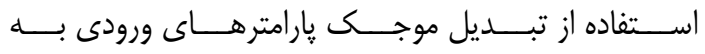

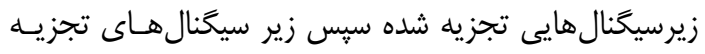

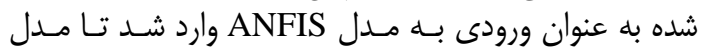

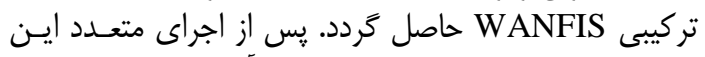

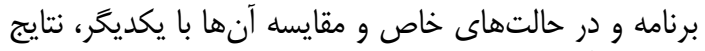

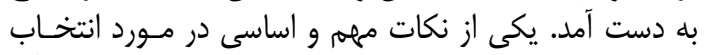



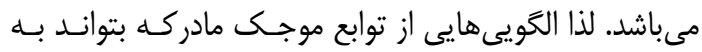

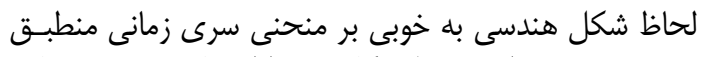

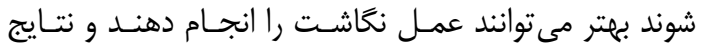

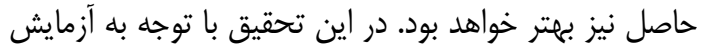
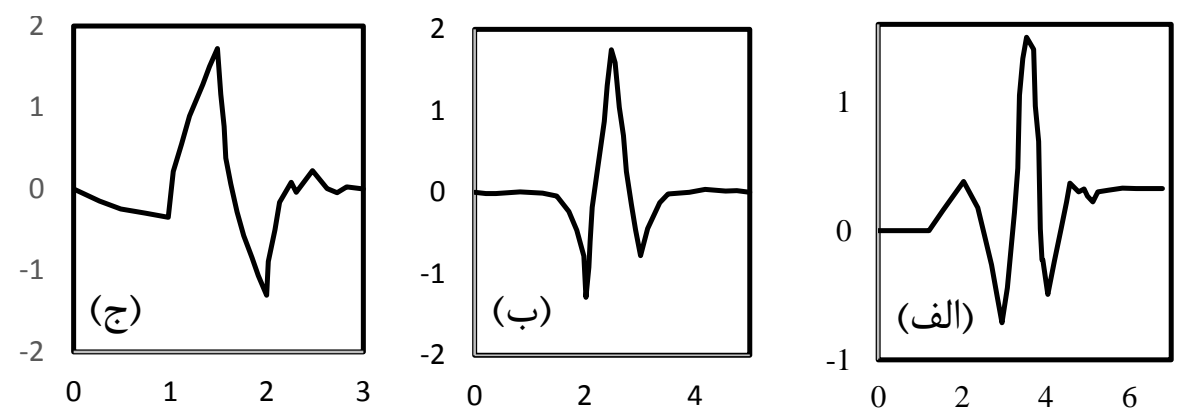

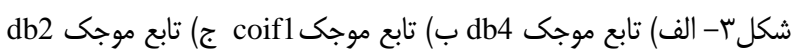

Figure 3. a) Harr wavelet b) Db4 wavelet c) Db2 wavelet 


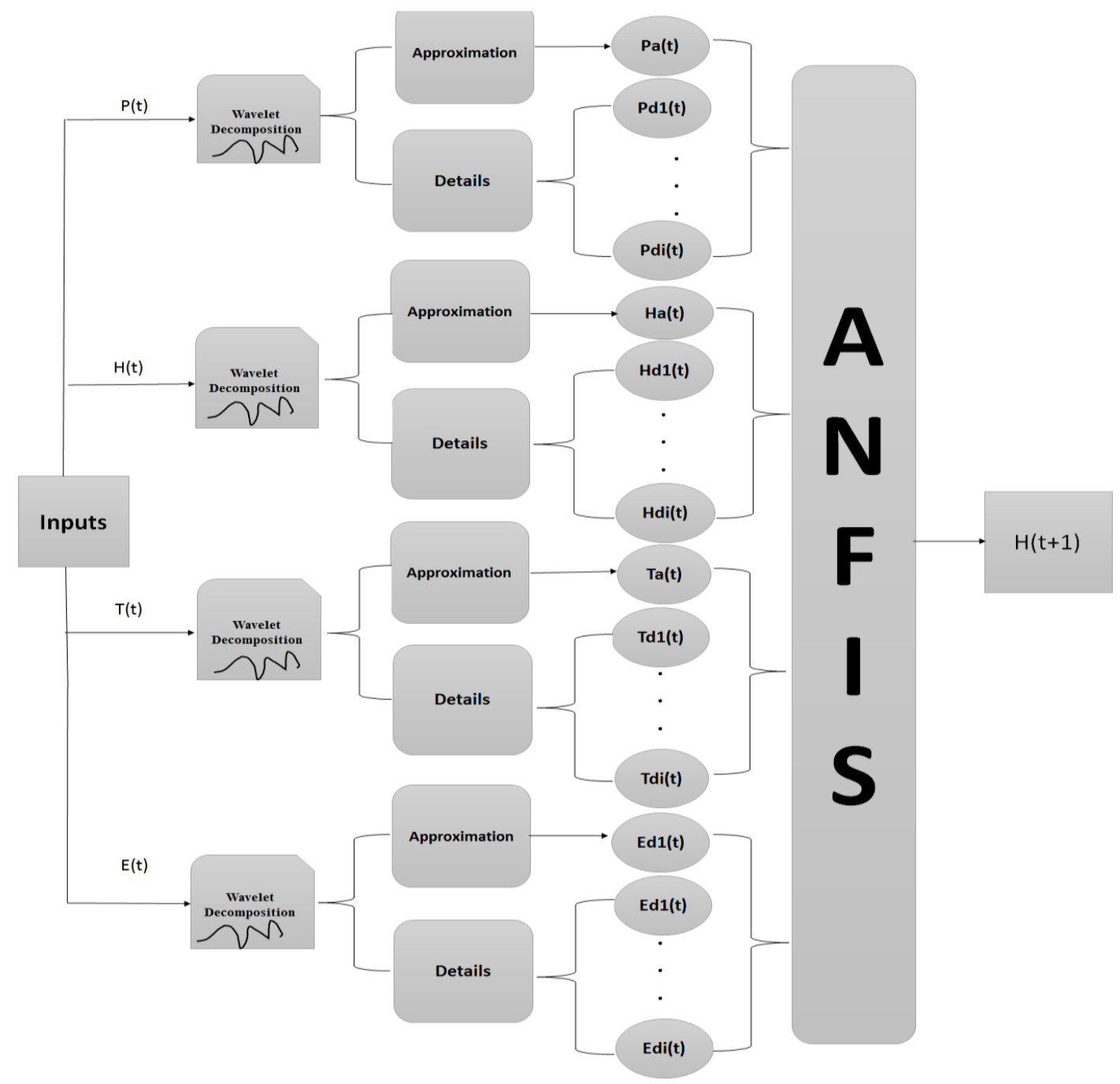

شكل ع - ساختار شماتيك مدل تر كيبى و نحوه ورود دادهها

Figure 4. Schematic structure of the hybrid model and data entry method

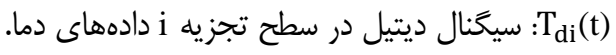
Ea(t)

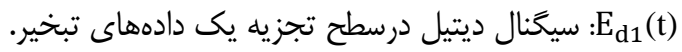

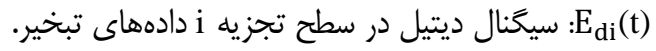

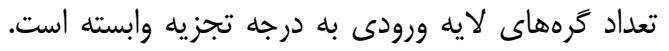

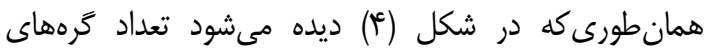

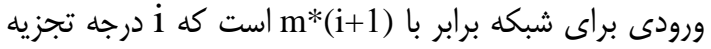

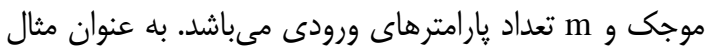



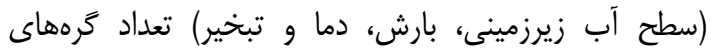

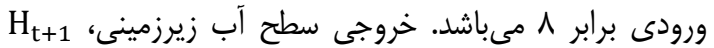

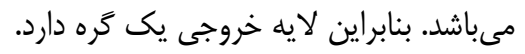



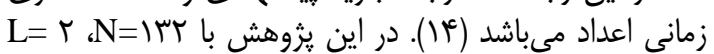

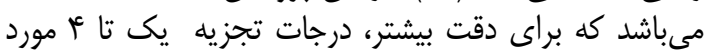

$$
\text { بررسى قرار زرفت. }
$$

يارامترهايى كه در شكل ديده مىشوند عبارتند از: Pa(t)

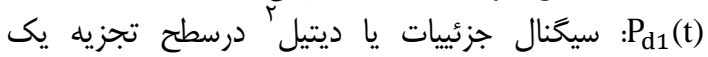
دادههاى بارش. سيخنال ديتيل در سطح تجزيه i دادههاى بارش. :Qa(t)

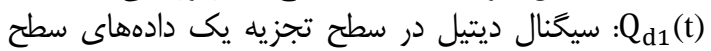
آب زيرزمينى.

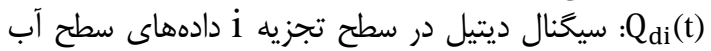

$$
\text { Ta(t) }
$$

Th1

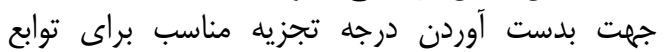
موجك از رابطه يبشنهادى زير ارائه شد.

$$
\mathrm{L}=\mathrm{Int}[\log (\mathrm{N})]
$$




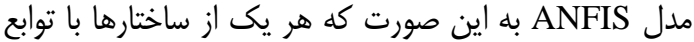

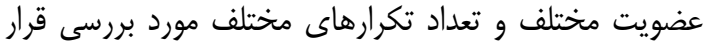



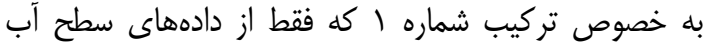

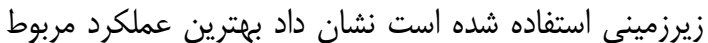

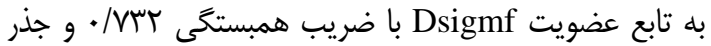

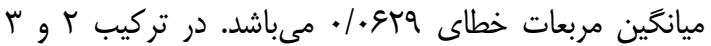

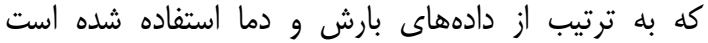





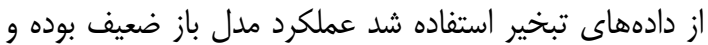

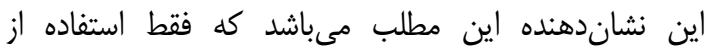

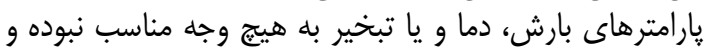

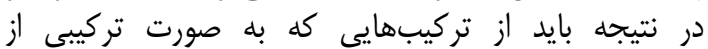

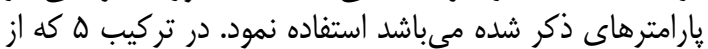

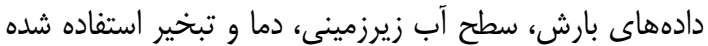

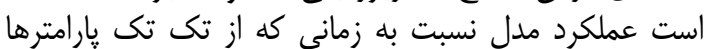



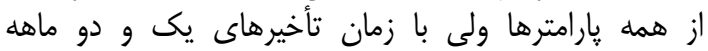

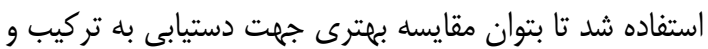





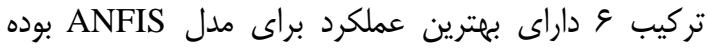

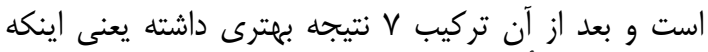

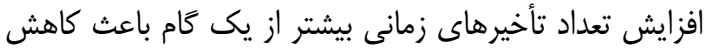
عملكر د مدل شده است.

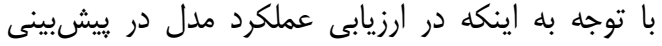

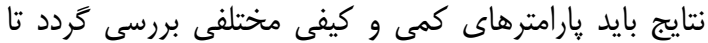

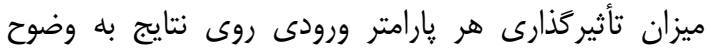

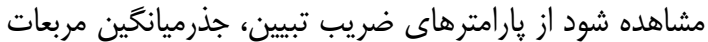

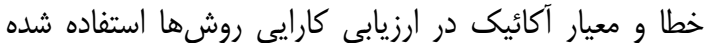
است كه روابط آنها به صورت زير ميان معاباشد.

$$
\begin{aligned}
& \text { RMSE }=\sqrt{\frac{\sum_{i=1}^{N}\left(H_{i}-H_{o}\right)^{2}}{N}} \\
& \mathrm{R}^{2}=1-\frac{\sum_{\mathrm{i}=1}^{\mathrm{N}}\left(\mathrm{H}_{\mathrm{o}}-\mathrm{H}\right)^{2}}{\sum_{\mathrm{i}=1}^{\mathrm{N}}\left(\mathrm{H}_{\mathrm{o}}-\overline{\mathrm{H}}\right)^{2}}
\end{aligned}
$$

$$
\mathrm{AIC}=\mathrm{m} \times \ln (\mathrm{RMSE})+2(\mathrm{Npar})
$$

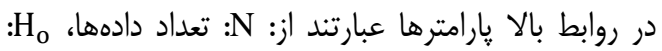
دادهاى مشاهداتى،


دادههاى آموزش ديده مى مباشد.

\section{نتايج و بحثث نتايج مدلسازى مدل ANFIS} ساختارهاى مختلف در هر يك از تركيبهاى مختلف

\begin{tabular}{|c|c|c|c|c|c|c|c|}
\hline \multicolumn{2}{|c|}{ جذر ميانگين مربعات خطا } & \multicolumn{2}{|c|}{ ضريب همبستكى } & \multirow{2}{*}{ تعداد تكرار } & \multirow{2}{*}{$\begin{array}{l}\varepsilon \dot{ } \\
\text { Mf }\end{array}$} & \multirow{2}{*}{ تابع عضويت } & \multirow{2}{*}{ تركيب } \\
\hline آزمون & آموزش & آزمون & آموزش & & & & \\
\hline .1 .949 & אEMr.|. & . &.$/ 949$ & r. & Constant & Dsigmf & 1 \\
\hline سות/א. & $.1 .94 T$ & . $/ \Delta T$. & $\cdot / V \cdot r$ & $r$. & Constant & Pimf & r \\
\hline$\cdot / r \mid 1 /$ & $.1 .9 \Delta \Delta$ &.$/ 4 I r$ & .1919 & r. & Constant & Pimf & r \\
\hline.$/ 11 k 1$ &.$/ \cdot V^{\mu}$ & . / $Q 9$. &.$/ 911$ & נr & Constant & Guassmf & $\Delta$ \\
\hline $.1 . \Delta F F$ & . H ra & ./var &.$/ 999$ & 1. & Constant & Trapmf & \& \\
\hline . $1 \cdot 9 \cdot r$ & .. TED & $\cdot / \mathrm{VV}$ &.$/ १ \Delta \&$ & 10 & Linear & Guass $2 \mathrm{mf}$ & $v$ \\
\hline
\end{tabular}

جدول F- بهترين ساختار در تركيبهاى مختلف مدل ANFIS براى قاه ا Table 4. The best structure for different combinations of ANFIS model for well No. 1

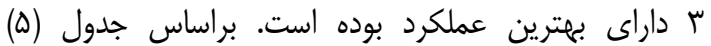

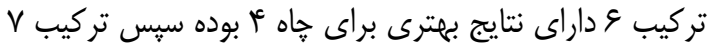

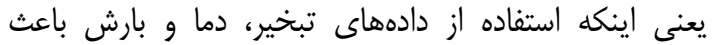

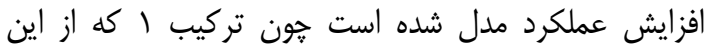

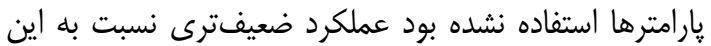



بهترين ساختار براى هر يك از تركيبهاى هفت أمانه



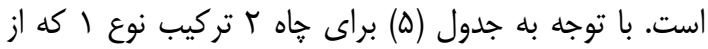

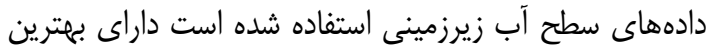



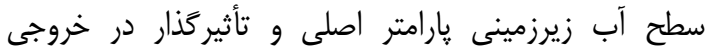
مىباشد. با توجه به اين جدول ساختار برتر تركيب و براي تراه 
Table 5. The best structure for different combinations of ANFIS model for defferent wells

\begin{tabular}{|c|c|c|c|c|c|c|c|c|}
\hline \multicolumn{2}{|c|}{ جذرميانخين مربعات خطا } & \multicolumn{2}{|c|}{ ضريب همبستگى } & \multirow{2}{*}{ تعداد تكرار } & \multirow{2}{*}{$\begin{array}{l}\varepsilon g^{\prime} \\
\text { Mf }\end{array}$} & \multirow{2}{*}{ تابع عضويت } & \multirow{2}{*}{ تركيب } & \multirow{2}{*}{ جاه } \\
\hline آزمون & آموزش & آزمون & آموزش & & & & & \\
\hline$\cdot 1 \cdot \Delta F F^{2}$ &.$/ \cdot r Q$ &.$/$ Vq4 &.$/ 999$ & 1. & Constant & Trapmf & 9 & 1 \\
\hline $.1 \cdot 1 V 9$ & .1 .099 & س4 &.$/ 994$ & r. & Linear & Dsigmf & 1 & r \\
\hline שותי/. & שחז./. & $\cdot / \Lambda \Delta V$ &.$/ 9 \& \Delta$ & $\Delta$ & Constant & Trapmf & \& & r \\
\hline (. & אוt. &.$/ 119$ &.$/ 901$ & 10 & Constant & Pimf & 8 & f \\
\hline .1 .140 & .1 .119 & - /Arq &.$/ 990$ & 1. & Constant & Guass $2 \mathrm{mf}$ & 8 & $\Delta$ \\
\hline
\end{tabular}

نتايج مدلسازى با مدل تركيبى

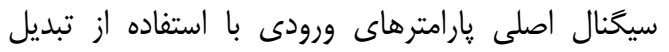

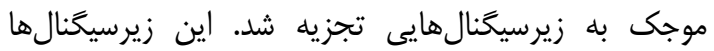

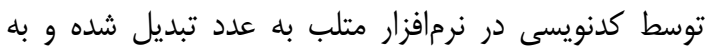

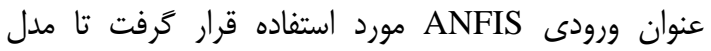

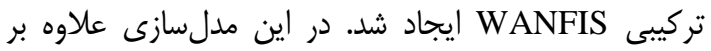





شود.

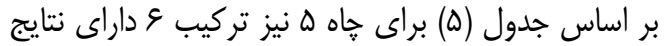



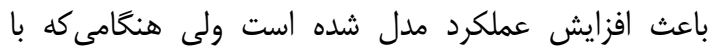

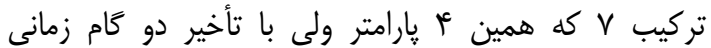

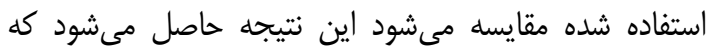

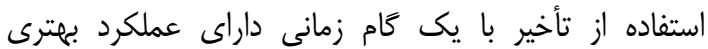

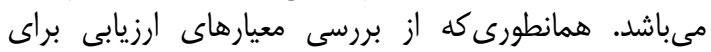

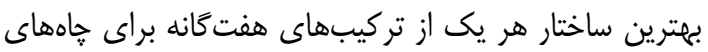

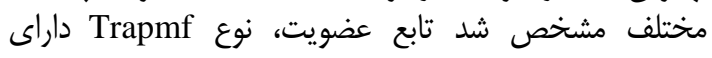
بهترين عملكرد بوده است.

Table 6. Results of WANFIS model for different wavelets for different wells

جدول צ- نتايج بANFIS براى موجكهاى مختلف براى خامهاى مختلف

\begin{tabular}{|c|c|c|c|c|c|c|c|c|}
\hline \multicolumn{2}{|c|}{ جذر ميانكين مربعات خطا } & \multicolumn{2}{|c|}{ ضريب همبستى } & \multirow{2}{*}{ تكرار } & \multirow{2}{*}{ تابع عضويت } & \multirow[b]{2}{*}{ درجه تجزيه } & \multirow[b]{2}{*}{ ن نوع موجى } & \multirow{2}{*}{ جاه } \\
\hline آزمون & أموزش & أزمون & أموزش & & & & & \\
\hline$\cdot / \cdot \mathrm{rQV}$ & .1 .499 & ( &.$/ 909$ & 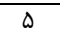 & Trapmf & $r$ & $\mathrm{Db} 4$ & 1 \\
\hline .1 .119 & זrו./. &.$/ 911$ &.$/ 2 \wedge \varepsilon$ & 10 & Pimf & r & Db4 & r \\
\hline.$/ .109$ &.$/ .1 \% 1$ & $.90 T$ &.$/ 991$ & $r$. & Dsigmf & r & $\mathrm{Db} 2$ & r \\
\hline 䅦 & . & שצר/. &.$/ 9 \vee$. & 10 & Guass $2 \mathrm{mf}$ & r & Coif1 & f \\
\hline .1 .99 & .1 .19$. &.$/ 9 \Delta \Delta$ &.$/ 9 \wedge 8$ & 1. & Gbellmf & $r$ & Coif1 & $\Delta$ \\
\hline
\end{tabular}

با توجه به بهترين ساختار هر يك از مدلهاى استفاده


WANFIS

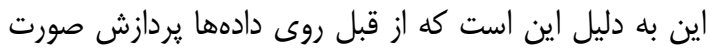

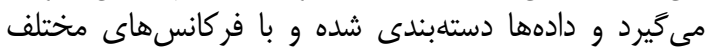
وارد ANFIS مى شى دهوند.
نتايج حاصل از مدلسازى با مدل تركيبى به ازاى توابع

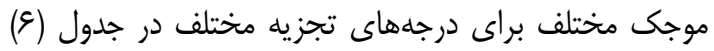

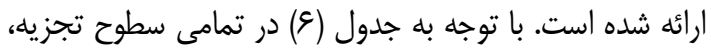

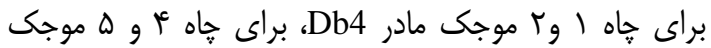

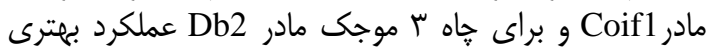



مقايسه مدل مهاى مختلف موجك

Table 7. Comparison of results obtained by different models

\begin{tabular}{|c|c|c|c|c|c|c|c|}
\hline \multicolumn{2}{|c|}{ جذر ميانگين مربعات خطا } & \multicolumn{2}{|c|}{ ضريب همبستخى } & \multicolumn{2}{|c|}{ ضريب آكائيى } & نام קاه & مدل \\
\hline$\cdot / \cdot \Delta G T^{q}$ &.$/ \cdot T \Delta$ & ./Vqq &.$/ 999$ & $f / / \ldots$ & $14 F / 14$ & 1 & ANFIS \\
\hline $.1 \cdot 1 V 8$ & $.1 . .99$ & . &.$/ 994$ & $\Delta) / \mathcal{M}$ & IVN/IV & r & ANFIS \\
\hline .1 .118 & אזו./. &.$/ 911$ &.$/ 9 \wedge 8$ & $r \Delta / 1 \varepsilon$ & $1 \cdot \Delta / \Gamma^{\mu}$ & r & WANFIS \\
\hline מוז./. & מחז•|. & $\cdot / \Lambda \Delta V$ &.$/ 990$ & (ז & $181 /\left.9\right|^{k}$ & r & ANFIS \\
\hline ه ه & T4t.|. &.$/ 119$ &.$/ 901$ & TN/IQ & $181 / 9$. & f & ANFIS \\
\hline אוtr/. &.$/ .104$ & س94. &.$/ 9 \mathrm{~V}$ & $r / 9 \Delta$ & ITV/AV & f & WANFIS \\
\hline$\cdot 1 \cdot 1 F \Delta$ & .1 .119 & ./ATq &.$/ 990$ & $\Delta 1 / \Gamma$. & IVN/V. & $\Delta$ & ANFIS \\
\hline.$/ . q 4$ & .1 .19 &.$/ 9 \Delta \Delta$ &.$/ 918$ & V/१९ & IfF/FF & $\Delta$ & WANFIS \\
\hline
\end{tabular}


مى شود كه مدل تركيبى در تمامى خاهها داراى جذر ميانكين



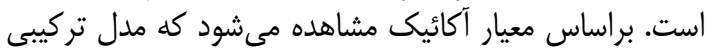



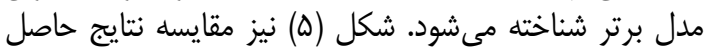

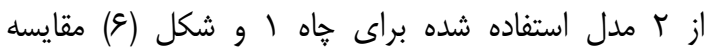

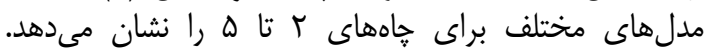

با توجه به جدول فوق در تمامى خاههاى مشاهدهاى

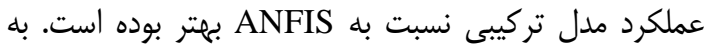

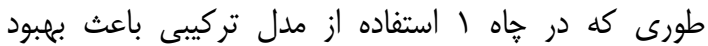

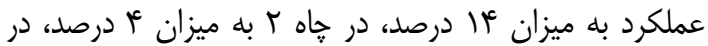

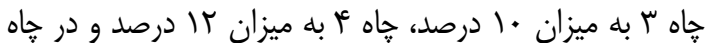

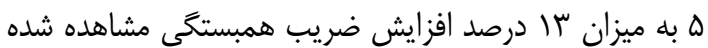
است. با توجه به يارامتر جذر ميانكين مربعات خطا نيز ميز مشاهده

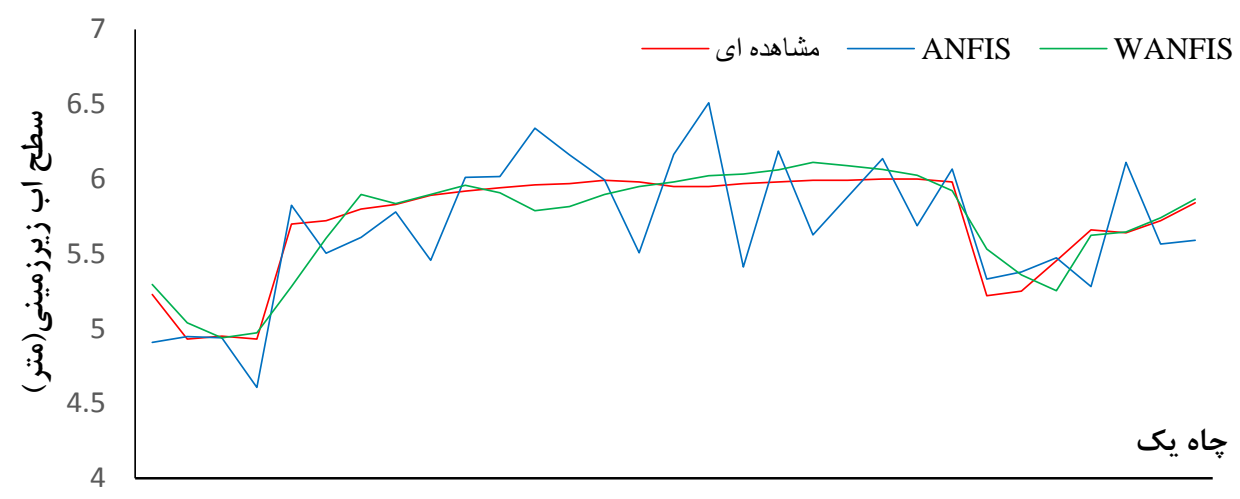

12334566789910111213141516171819202122232425262728293031

زمان(ماه)

شكل ه- مقايسه نتايج حاصل از مدلهاى مختلف- مرحله آزمون - خاه إماه

Figure 5. Comparison of results obtained by different models, test stage, well No.1

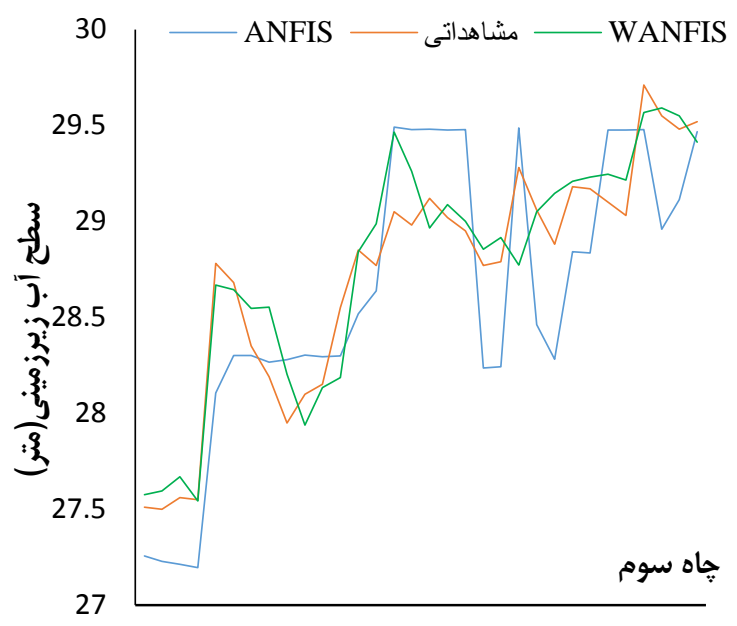

1355791113151719212325272931

زمان(ماه)



شكل צ- مقايسه نتايج حاصل از مدلهاى مختلف- مرحله آزمون - حاههاى ب تا هـ

Figure 6. Comparison of results obtained by different models, test stage, wells No.1 to 4 


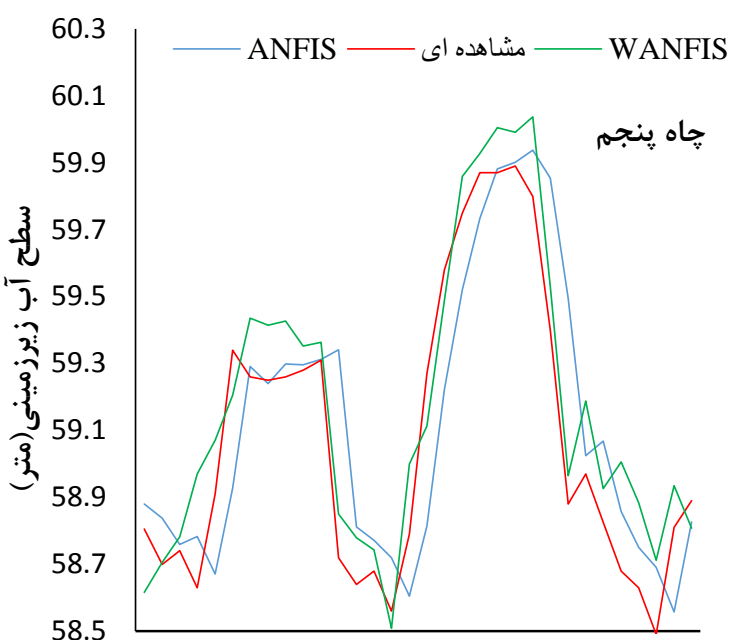

1335791113151719212325272931 زمان(ماه)

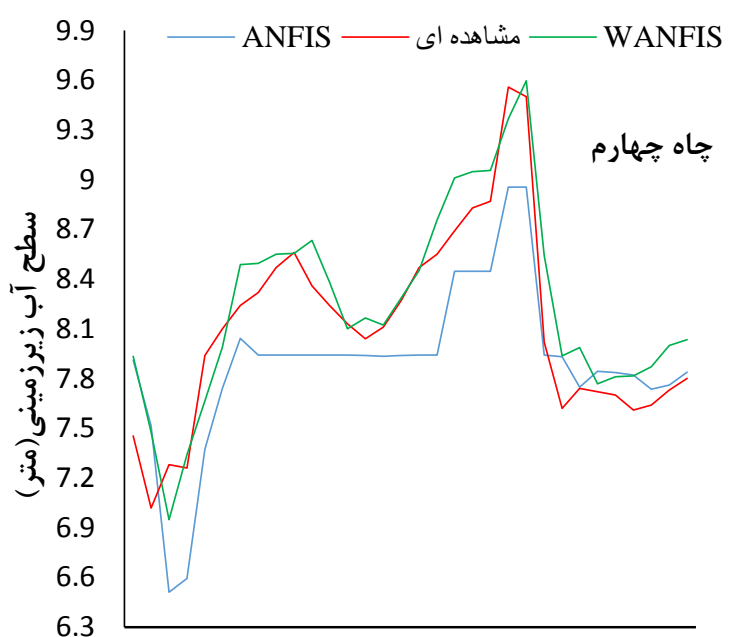

1355791113151719212325272931

زمان(ماه)



Cotinued Figure 6. Comparison of results obtained by different models, test stage, wells No.1 to 4

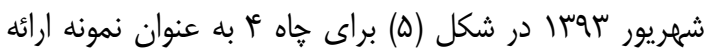



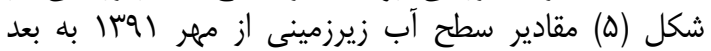

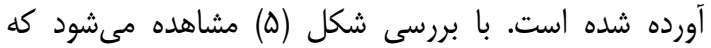

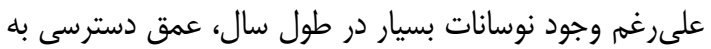

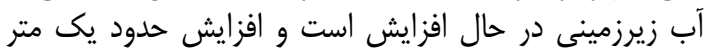

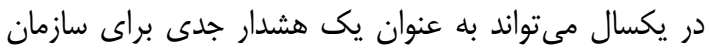

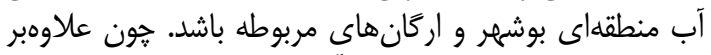





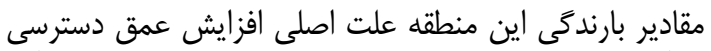

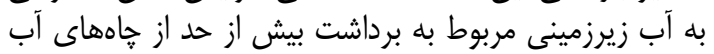
زيرزمينى منطقه مىباشد.
همانطورى كه در شكلهاى فوق مشخص است مدل

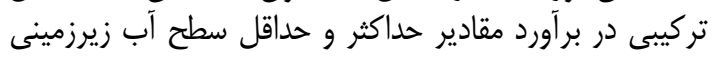
نسبت به مدل ANFIS عملكرد بهترى داورد داشته است. همرِنين مشاهده مىشود كه مقادير برآوردى مدل مدل تركيبى به به مقدي مقادير

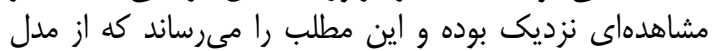

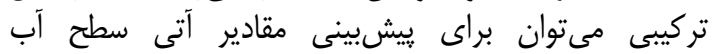



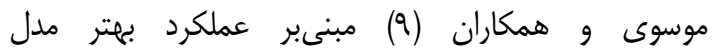
WANFIS

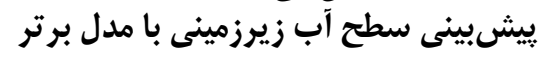

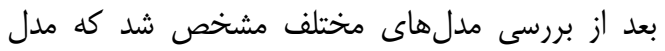

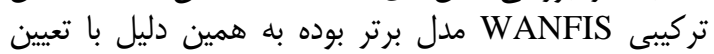

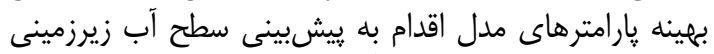






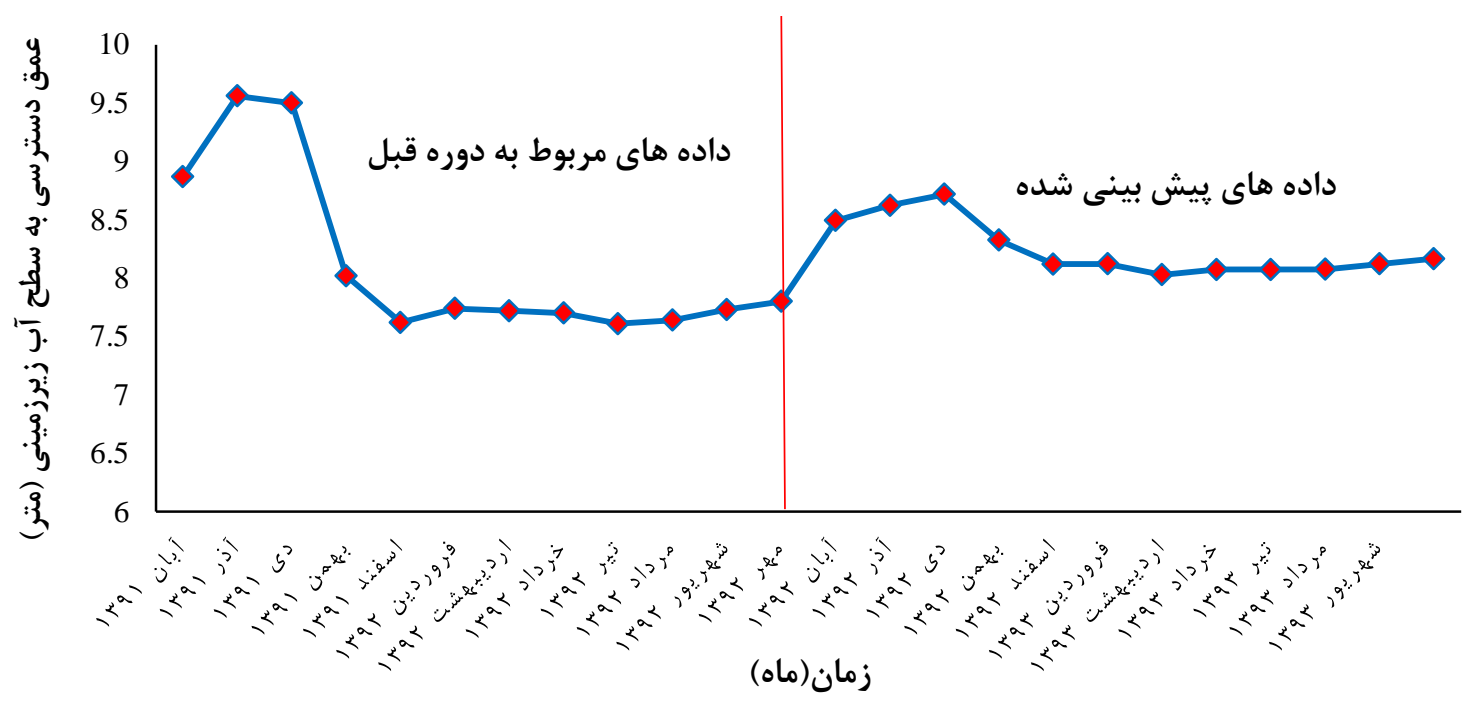

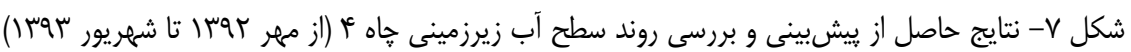

Figure 7. Results of obtained by prediction and check trend groundwater for well No.4 (October 2013 to September 2014)

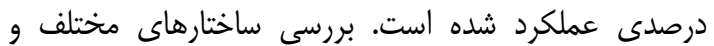

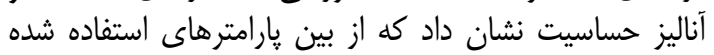

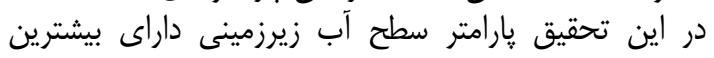



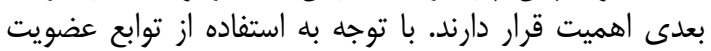

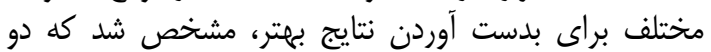

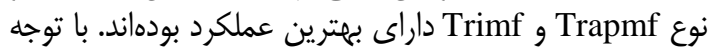

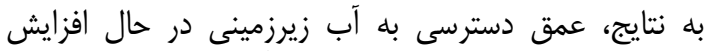



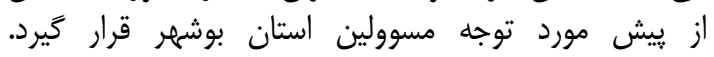

در اين تحقيق از مدلهاى ANFIS و WANFIS براى



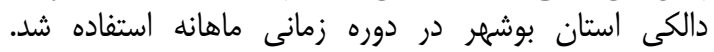


Coif1

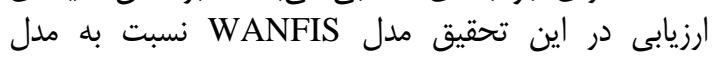
ANFIS



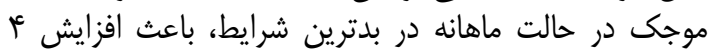

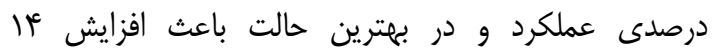


1. Adamowski, J. and H.F. Chan. 2011. A wavelet neural network conjunction model for groundwater level forecasting. Journal of Hydrology, 407(1-4): 28-40.

2. Afruzi, A., Zare Abyaneh, H. 2017. Groundwater Level Modeling and Forecasting using the Time Series Models (Case Study: The Plains of Hamadan Province). Journal of Watershed Management Research, 8(15): 102-111 (In Persian).

3. Ebrahimi, H., T. Rajaee. 2017. Simulation of groundwater level variations using wavelet combined with neural network, linear regression and support vector machine. Global and Planetary Change, 148:181-191.

4. Fallah-Mehdipour, E., O. Bozorg Haddad and M.A. Mariño. 2013. Prediction and simulation of monthly groundwater levels by genetic programming. Journal of Hydro-Environment Research, 7(4): 253-260.

5. Izadi, A., K. Davari, A. Alizadeh, B. Ghahreman, V. Haghayeghi and S.A. Moghaddam. 2007. Estimation groundwater Level Using Artificial Neural Network. Irrigation and Drainage Journal of Iran, 71(2): 1-59 (In Persian).

6. Jang, J.S.R., C.T. Sun, E. Mizutani. 1997. Neuro-Fuzzy and Soft Computing: A Computational Approach to Learning and Machine Intelligence. Prentice-Hall International, New Jersey.

7. Kiși, Ö. 2009. Evolutionary fuzzy models for river suspended sediment concentration estimation. Journal of Hydrology, 372(1-4): 68-79.

8. Mallat, S.G. 1998. A wavelet tour of signal processing, San Diego, 123 pp.

9. Moosavi, V., M. Vafakhah, B, Shirmohammadi and M. Ranjbar. 2014. Optimization of WaveletANFIS and Wavelet-ANN Hybrid Models by Taguchi Method for Groundwater Level Forecasting. Arabian Journal for Science and Engineering, 39: 1785-1796.

10. Nakhai, M., A. Saberi Nasr and R. Farajzadeh. 2011. Advantages of Neural-Wavelet Network in Forecasting of Groundwater Fluctuations. Fourth Conference of Iranian Water Resources Management. Amirkabir University of Technology Tehran, (In Persian).

11. Nayak, P., Y.R. Satyaji Rao and K.P. Sudheer. 2006. Groundwater Level Forecasting in a Shallow Aquifer Using Artificial Neural Network Approach. Water Resources Management, 20: 77-90.

12. Nayak, P.C., K.P. Sudheer, D.M. Rangan and K.S. Ramasastri. 2004. A neuro-fuzzy computing technique for modeling hydrological time series. Journal of Hydrology, 291(1-2): 52-66.

13. Nourani, V., A. Asghari Mogaddam and A.O. Naderi. 2008. An ANN-based model for spatiotemporal groundwater level forecasting. Hydrological Processes, 22: 5054-5066.

14. Nourani, V., M. Komasi and A. Mano. 2009. A Multivariate ANN-Wavelet Approach for RainfallRunoff Modeling. Water Resources Management, 23: 2877-2894.

15. Nourani, V. and S. Mousavi. 2016. Spatiotemporal groundwater level modeling using hybrid artificial intelligence-meshless method. Journal of Hydrology, 536: 10-25.

16. Rajai, T. and A. Zenivand. 2014. Modeling groundwater level using a wavelet hybrid modelartificial neural network (case study: Sharif Abad plain). Civil Engineering and Environment Journal, 44(3): 77: 63-51 (In Persian).

17. Ramezani-Charmahineh, A. and M. Zounemat-Kermani. 2017. Evaluation of the Efficiency of Support Vector Regression, Multi-Layer Perceptron Neural Network and Multivariate Linear Regression on Groundwater Level Prediction (Case Study: Shahrekord Plain). Journal of Watershed Management Research, 8(15): 1-12 (In Persian).

18. Riad, S., J. Mania, L. Bouchaou and Y. Najjar. 2004. Rainfall-runoff model usingan artificial neural network approach. Mathematical and Computer Modelling, 40(7-8): 839-846.

19. Shiri, J., O. Kisi, H. Yoon, K.K. Lee and A. Hossein Nazemi. 2013. Predicting groundwater level fluctuations with meteorological effect implications-A comparative study among soft computing techniques. Computers \& Geosciences, 56(0): 32-44.

20. Solgi, A. 2014. Predict river flow with hybrid model wavelet-artificial neural network and compraction it with adaptive neuro fuzzy inference system and artificial neural network (case study: Nahavand Gamasiyab river). M.Sc.Thesis, Shahid Chamran University of Ahvaz, Ahvaz, Iran, 164 pp (In Persian).

21. Suryanarayana, C., C. Sudheer, V. Mahammood and B.K. Panigrahi. 2014. An integrated waveletsupport vector machine for groundwater level prediction in Visakhapatnam, India. Neurocomputing, 145: 324-335.

22. Toolbox of the MATLAB software, R2013a.

23. Wang, W. and J. Ding. 2003. Wavelet Network Model and Its Application to the Prediction of Hydrology. Natureand Science, 1(1): 67-71.

24. Zadeh, L.A. 1965. Fuzzy Sets. Information and control, 8(3): 338-353. 


\title{
Evaluation of Combined ANFIS with Wavelet Transform to Modeling and Forecasting Groundwater Level
}

\author{
Ali Eskandari ${ }^{1}$, Farshad Faramarzyan Yasuj ${ }^{2}$, Abazar Solgi $^{3}$ and Heidar Zarei ${ }^{4}$
}

1- Instructor, Department of Civil Engineering, Faculty of Engineering, Islamic Azad University of Bushehr, Iran.

2- Graduated MSc. Student, Department of Irrigation and Drainage, Faculty of Water Sciences Engineering, Shahid Chamran University of Ahvaz, Iran.

3- Corresponding author, Ph.D. Student, Department of Water Resources Engineering, Faculty of Water Sciences Engineering, Shahid Chamran University of Ahvaz, Iran (Corresponding author: abazar_solgi@ yahoo.com).

4- Associate Professor, Department of Hydrology and Water Resources, Faculty of Water Sciences Engineering,

Shahid Chamran University of Ahvaz, Iran.
Recieved: December 19, $2017 \quad$ Accepted: May 29, 2018

\begin{abstract}
One of the most important factors. in a good management in anv field. is having a proper perspective of the uncoming events. There is no exception in water resources management and the environment and awareness of the condition of water resources. in an area. plavs a decisive role for planning water and agriculture. In this studv. the Adantive Neural Fuzzv Inference Svstem (ANFIS) was used for the monthlv forecast of Dalaki Basin groundwater levels in the province Bushehr in a 12-vear neriod (2002- 2013). In order to improve the results of the model. the wavelet transform was used and the original signal was decomnosed to sub-signals. Then. sub-signals were entered. as invut. into ANFIS model to obtain the hvbrid model. WaveletAdantive Neural Fuzzv Inference Svstem (WANFIS). To forecast the groundwater level of five observed wells has been used. using groundwater levels. precinitation. evanoration. andtemperature. Results showed that hvbrid model. WANFIS. has better performance than ANFIS model. Also. it was showed that hvbrid model has better nerformance in estimate extreme noints. So. this method. using wavelet theorv. increased the nerformance bv $14 \%$. At the end. groundwater levels were estimated bv the best model in a vear. The results of thepredicted groundwater levels showed that theincrease of having access to groundwater in the Dalaki area. This problem is noted to authorities of the area regarding the effects on water resources and the environment of the area.
\end{abstract}

Keyword: Hybrid model, Wavelet Transform, Groundwater Level, Dalaki basin, Modeling and Forecasting 